\title{
Время жизни избыточного электрона в порошках $\mathrm{Cu}-\mathrm{Zn}-\mathrm{Sn}-\mathrm{Se}$
}

\author{
(C) Г.Ф. Новиков ${ }^{1}$, М.В. Гапанович ${ }^{1}$, В.Ф. Гременок ${ }^{2}$, К.В. Бочаров ${ }^{1}$, W.-T. Tsai ${ }^{3}$, \\ Ming-Jer Jeng ${ }^{3}$, Liann-Be Chang ${ }^{3}$ \\ ${ }^{1}$ Институт проблем химической физики Российской академии наук, \\ 142432 Черноголовка, Россия \\ ${ }^{2}$ Научно-практический центр Национальной академии наук Беларуси по материаловедению, \\ 220072 Минск, Республика Беларусь \\ ${ }^{3}$ Department of Electronic Engineering, Chang Gung University, \\ Taoyuan, Taiwan \\ E-mail: ngf@icp.ac.ru
}

(Получена 13 апреля 2016 г. Принята к печати 28 апреля 2016 г.)

Методом время-разрешенной микроволновой фотопроводимости в диапазоне 36 ГГц в интервале температур 200-300 K изучена кинетика гибели носителей тока в порошках $\mathrm{Cu}-\mathrm{Zn}-\mathrm{Sn}-\mathrm{Se}$, полученных ампульным твердофазным методом синтеза. Время жизни избыточных электронов при комнатной температуре оказалось меньше 5 нс. Энергия активации для процесса рекомбинации составила $E_{a} \sim 0.054$ эВ.

DOI: 10.21883 /FTP.2017.01.43990.8274

\section{1. Введение}

Тонкопленочные солнечные элементы (ТСЭ) привлекают все большее внимание исследователей всего мира прежде всего надеждой на снижение цены производимой электроэнергии. Особенно сказанное относится к батареям с поглощающими слоями $\mathrm{Cu}-\mathrm{In}-\mathrm{Ga}-(\mathrm{S}, \mathrm{Se})$ (CIGS) и CdTe, которые уже начинают внедряться в производство [1]. Однако, несмотря на перспективу этих технологий, относительно небольшая распространенность в природе In и Те ограничивает производственные мощности для батарей на их основе по прогнозам до < $100 \mathrm{GWP}$ в год. Более низкая стоимость руд, содержащих медь, цинк или олово - основу кестеритов $\mathrm{Cu}_{2} \mathrm{ZnSn}(\mathrm{S}, \mathrm{Se})_{4}(\mathrm{CZTSe})$ - делает их привлекательной альтернативой для CdTe или CIGS.

Существует несколько способов получения пленок данных материалов, основные из них: вакуумное испарение $[2,3]$, соиспарение $[4,5]$, золь-гель метод [6,7] и электроосаждение [8]. Достаточно успешный подход, основанный на спин-коутинге из раствора частиц в гидразине, был предложен компанией IBM для изготовления фотоэлектрических устройств с КПД более $11.1 \%$ на основе $\mathrm{Cu}_{2} \mathrm{ZnSn}(\mathrm{S}, \mathrm{Se})_{4}$ [6]. В литературе также имеются данные о создании солнечной батареи на основе $\mathrm{Cu}_{2} \mathrm{ZnSnSe}_{4}$ с эффективностью 9.15\%, поглощающий слой которой был получен методом соиспарения из 4 источников [4]. Однако, несмотря на успехи в создании ТСЭ, достигнутые показатели все же в 3 раза хуже теоретического предела Шоккли-Квиссера $(\sim 30 \%)$ [9] и причины этого неясны.

Можно предположить, что низкий коэффициент конверсии в сравнении с теоретическим пределом обусловлен узостью области гомогенности $\mathrm{CZTS}(\mathrm{Se})[10,11]$, которая обусловливает трудности в получении однофазных пленок $\mathrm{CZTS}(\mathrm{Se})$ с минимальными отклонениями элементного состава от стехиометрии. В ряде работ, однако, показана возможность получения монокристал- лов CZTS и CZTSe, обогащенных Zn. Однофазность данных кристаллов подтверждена методами рентгенофазового анализа (РФА) и спектроскопии комбинационного рассеяния света (КРС) [12,13]. Кроме того, в независимости от метода получения прекурсоров было установлено, что ТCЭ на основе пленок CZTS, обогащенных цинком и обедненных медью, показывают более высокие значения эффективности фотопреобразования по сравнению с ТСЭ на основе стехиометрических пленок CZTS [14-16]. В ряде работ было показано, что оптимальными в плане эффективности ФЭП являются соотношения компонентов $\mathrm{Cu} /(\mathrm{Zn}+\mathrm{Sn})=0.75-0.9$, $\mathrm{Zn} / \mathrm{Sn}=1.10-1.3, \mathrm{Cu} / \mathrm{Sn}=1.8-2.0, \mathrm{~S} /$ металлы $=1.05$ и $\mathrm{Zn}$ /металлы $=0.25-0.31$ [17-19].

Один из подходов к объяснению причины влияния дефицита меди на эффективность ТСЭ на основе CZTS основан на различии структурных дефектов в обедненном медью и стехиометрическом CZTS. В обедненном медью материале основным дефектом являются вакансии меди $V_{\mathrm{Cu}}$, в то время как в стехиометрическом CZTS основным типом дефектов ввиду меньшей энергии формирования является $\mathrm{Cu}_{\mathrm{Zn}}$. Энергия активации $V_{\mathrm{Cu}}$ составляет 0.02 эВ, поэтому при комнатной температуре большая часть дефектов ионизирована. Энергия активации $\mathrm{Cu}_{\mathrm{Zn}}$ составляет 0.11 эB [20], поэтому дефекты в стехиометрическом CZTS при комнатной температуре ионизированы в минимальной степени, что приводит к росту удельного сопротивления и, как следствие, росту последовательного сопротивления ТСЭ. В результате эффективность ТСЭ на основе стехиометрического CZTS может снижаться по сравнению с CZTS, обедненным медью.

С другой стороны, в стехиометрическом и обедненном составе могут существенно различаться не только концентрации, но и пространственные распределения дефектов, что может влиять на дрейфовые подвижности и времена жизни носителей тока и процессы разделения зарядов. Определенные указания на это были полу- 
чены при исследованиях зависимости микроволновой фотопроводимости от размеров областей когерентного рассеяния рентгеновских лучей (ОКР) в родственной системе CIGS [21]. Приготовление аналогичной серии образцов CZTS(Se) с разными размерами ОКР является существенно более сложной задачей из-за возможного присутствия станнитной фазы, трудно определяемой методом РФА, но создающей барьеры для движения зарядов на межфазных границах. Кроме того, прецизионный контроль соотношения металлов сам по себе является сложной задачей в ряде методов получения пленок CZTS(Se) (в частности, в методе термического испарения [22]), что создает трудности в сравнении образцов с разными размерами ОКР. Например, известно, что испарение при температурах выше $350^{\circ} \mathrm{C}$ приводит к потерям $\mathrm{Zn}$ и $\mathrm{Sn}$. Потери летучих компонентов возможны не только при получении пленки одностадийным методом термического испарения, но также и при сульфуризации/селенизации прекурсоров.

Поэтому в данной работе для получения CZTSe применен метод твердофазного синтеза („solid state reaction method“ - SSR) [23], который имеет преимущество в отношении возможности синтеза очень чистых однофазных образцов $\mathrm{CZTS}(\mathrm{Se})$ с точным, заранее определенным соотношением элементов. Для измерений времени жизни фотогенерированных носителей тока применен метод микроволновой фотопроводимости, который, в отличие от люминесцентного метода [24], позволяет регистрировать как излучательные, так и безызлучательные процессы гибели. Предварительные результаты опубликованы в работе [25].

\section{2. Экспериментальная часть}

Синтез образцов CZTSe осуществлялся методом SSR в ампулах в три стадии. На первом этапе, коммерчески доступные элементы $\mathrm{Cu}, \mathrm{Zn}, \mathrm{Sn}$ и $\mathrm{Se}$ с чистотой $99.99 \%$ сплавлялись в стехиометрических соотношениях в вакуумированных кварцевых ампулах. Синтез проводился при $T \sim 1100^{\circ} \mathrm{C}$ в течение 3 ч. На втором этапе содержимое ампулы растиралось в агатовой ступке. На третьем этапе для стабилизации фазового состава порошки отжигались в вакуумированных кварцевых ампулах при $T \sim 550^{\circ} \mathrm{C}$ в течение 100 ч. Полученные образцы изучали методами РФА $\left(\mathrm{Cu}-K_{\alpha}\right)$, спектроскопии КРС и время-разрешенной микроволновой фотопроводимости (TRMC) на частоте 36 ГГц. Возбуждение фотопроводимости осуществляли азотным лазером с длиной волны 337 нм, длительность импульса 8 нс, при интенсивности света $3.5 \cdot 10^{14}$ фот/см ${ }^{2}$ за импульс.

\section{3. Результаты экспериментов}

Элементный состав полученных порошков CZTSe, a также соотношение элементов представлены в табл. 1 и 2. Из табл. 2 видно, что образцы были обедненные медью и обогащенные цинком. Полученный состав лежит
Таблица 1. Элементный состав CZTSe

\begin{tabular}{c|c|c|c}
\hline $\mathrm{Cu}$ & $\mathrm{Zn}$ & $\mathrm{Sn}$ & $\mathrm{Se}$ \\
\hline $24.7 \%$ & $15.1 \%$ & $14 \%$ & $46.2 \%$
\end{tabular}

Таблица 2. Соотношение элементов в образце

\begin{tabular}{c|c|c|c|c}
\hline $\mathrm{Cu} /(\mathrm{Zn}+\mathrm{Sn})$ & $\mathrm{Zn} / \mathrm{Sn}$ & $\mathrm{Cu} / \mathrm{Sn}$ & $\mathrm{Se} /$ металл & $\mathrm{Zn} /$ металл \\
\hline 1.08 & 1.76 & 0.85 & 0.86 & 0.28
\end{tabular}

в диапазоне, в котором возможно достижение высокой эффективности солнечной батареи на его основе.

Рентгенограммы полученных порошков показаны на рис. 1. Пики CZTSe с максимумами 27.1 (112), $45^{\circ}$ (204) и $53.3^{\circ}$ (312) ярко выражены. На рис. 2 представлены спектры КРС полученных образцов. Основное колебание с максимумом при $189 \mathrm{~cm}^{-1}$, относящееся к CZTSe, хорошо выражено. Присутствуют также и более

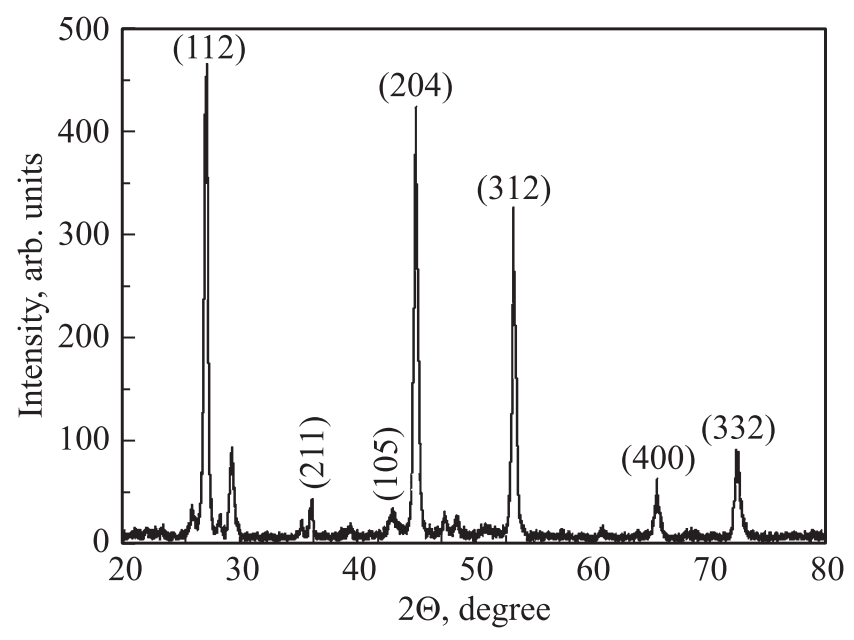

Pис. 1. Рентгенограмма CZTSe.

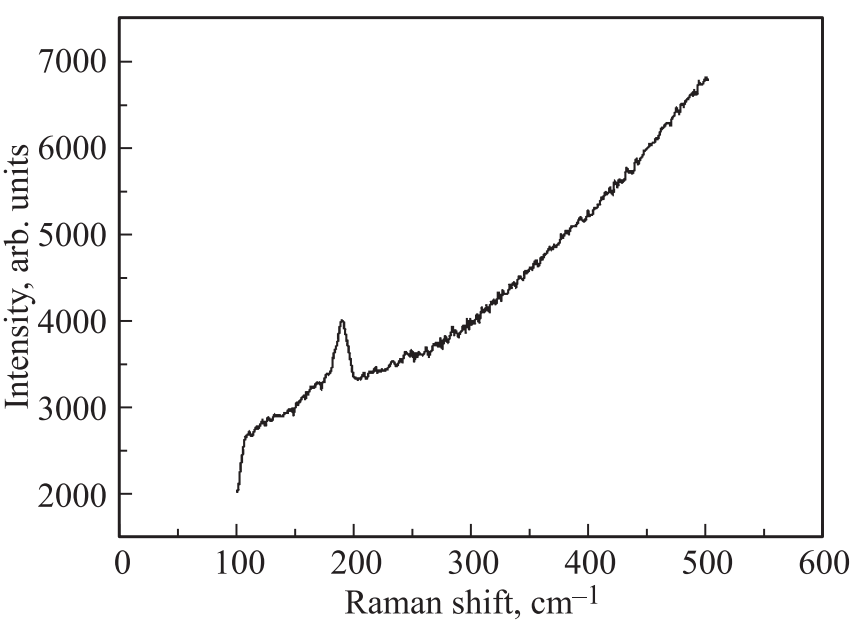

Рис. 2. Спектры КРС 


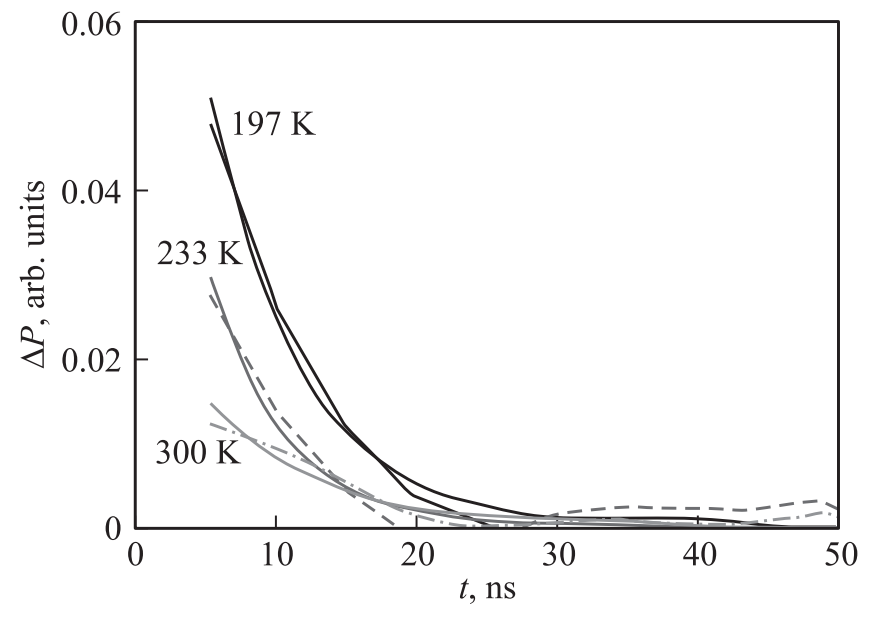

Рис. 3. Спады СВЧ-фотопроводимости при температурах 197 , 233 и $300 \mathrm{~K}$.

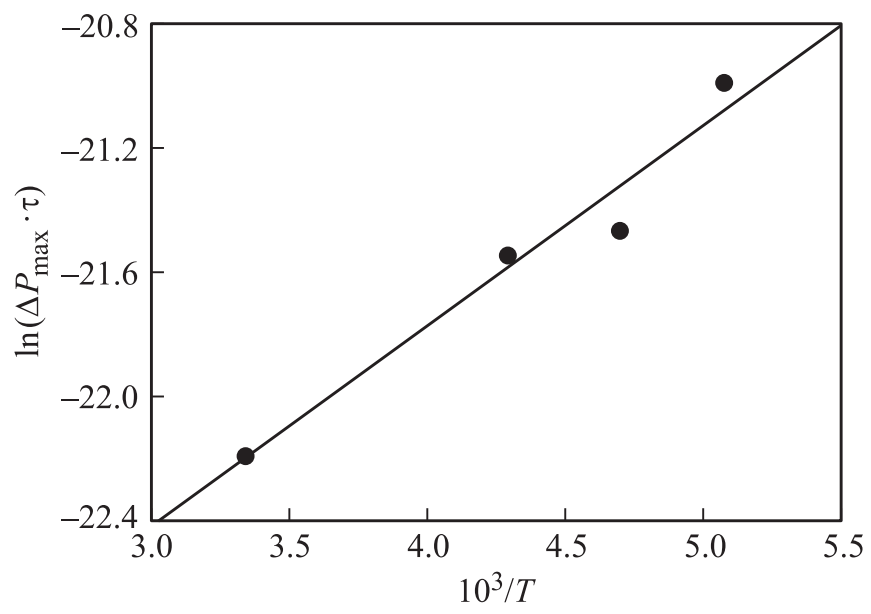

Рис. 4. Зависимость произведения амплитуды фотоотклика на характеристическое время спада фотоотклика от температуры.

слабые пики около 170 и $230 \mathrm{~cm}^{-1}$, которые наблюдаются при масштабировании. На рис. 3 показаны спады микроволновой фотопроводимости при $T=197,233$ и $300 \mathrm{~K}$. Фотоотклики TRMC имели чрезвычайно малую амплитуду и содержали значительные шумы (на рисунке показаны сглаженные кривые).

Понижение температуры приводило к возрастанию амплитуды фотоотклика, но времена спадов оставались неизменными (порядка 6 нс). Полученные значения времени спада были на грани временно́го разрешения установки. Можно сделать вывод, что времена спадов фотооткликов в порошках кестеритов были менее 6 нс вплоть до $T \sim 200 \mathrm{~K}$, а температурная зависимость амплитуды фотоотклика была обусловлена изменениями характеристических времен гибели избыточных носителей тока.

Зависимость произведения амплитуды на характеристическое время спада фотоотклика от температуры в аррениусовских координатах показана на рис. 4. Оценка энергии активации процесса гибели носителей тока из приведенного графика дает $E_{a} \approx 0.054$ эВ.

\section{4. Обсуждение}

Малые значения времен жизни фотогенерированных носителей тока были также зарегистрированы в работе [24] по измерениям время-разрешенной фотолюминесценции в сборках ТЭС. Наблюдались спады в виде двух экспоненциальных компонент. В ходе исследования было выявлено, что с уменьшением мощности лазера $(2,1,0.5 \mathrm{мBT})$ времена жизни первой компоненты $\tau_{1}$ возрастают с 0.45 до $0.60 \mathrm{Hc}$, а у второй компоненты $\tau_{2}$ возрастают с 1.65 до 2.5 нс. Такое влияние мощности лазера подразумевает заметный вклад в процессы гибели избыточных носителей тока процессов 2-го порядка кинетики, скорость которых зависит от начальных концентраций реагентов. Однако такое предположение плохо согласуется с анализом данных по кинетике люминесценции в работе [26]. В этой работе вторая компонента $\tau_{2}$ приписана временам жизни неосновных носителей тока в CZTS и описывает наличие дефектов в глубине зерен, а также на границах поглощающий слойбуферный слой и вблизи нижнего контакта. Первая компонента $\tau_{1}$ описывает высокоинжекционные процессы в CZTS, которые обусловливаются излучательными рекомбинационными процессами, а также перераспределением избытка носителей тока у поверхности образца.

Тем не менее следует обратить внимание на различие в энергиях активации: определенная по микроволновой фотопроводимости $E_{a}(\mathrm{TRMC}) \approx 0.054$ эВ не согласуется ни с энергией активации $E_{a}\left(\mathrm{~V}_{\mathrm{Cu}}\right) \approx 0.02{ }_{\ni} \mathrm{B}$, ни с энергией активации $E_{a}\left(\mathrm{Cu}_{\mathrm{Zn}}\right) \approx 0.11$ эВ. Естественно связать наблюдаемое различие в энергиях активации с тем, что микроволновые измерения делались на порошках, а другие на сборках ТЭС. Если принять это предположение, то время жизни, определяемое по микроволновой фотопроводимости, следует связывать с влиянием внутренней структуры зерна. Такое влияние может быть обусловлено неоднородным пространственным распределением дефектов, что может проявляться в эффективных размерах ОКР, определяемых по ширине линий в спектрах РФА [27,28].

\section{5. Заключение}

Таким образом в работе методом время-разрешенной микроволновой фотопроводимости (TRMC) в диапазоне 36 ГГц в интервале температур 200-300 К изучена кинетика гибели носителей тока в порошках $\mathrm{Cu}-\mathrm{Zn}-\mathrm{Sn}-\mathrm{Se}$, полученных методом ампульного твердофазного синтеза, т.е. в образцах, не содержащих ни металлических, ни других контактов. Время жизни избыточных электронов при комнатной температуре оказалось меньше 5 нс. Энергия активации для процесса рекомбинации составила $E_{a} \sim 0.054$ эВ. Эти результаты свидетельствуют о том, что наряду с описанными в литературе процессами гибели носителей тока вблизи электродов и на границе с буферным слоем, существенное влияние на поведение носителей тока оказывает внутренняя 
структура зерен. По-видимому в областях с „идеальной“ структурой, эффективный размер которых определяется как размер ОКР, носители тока живут больше 6 нс, но содержащиеся на границах ОКР дефекты из-за возрастания вклада процессов рекомбинации через локальные центры могут приводить к существенному уменьшению времени жизни носителей тока и соответственно к уменьшению диффузионной длины пробега. Последний параметр может существенно повлиять на фотовольтаические характеристики ТЭС, использующих в качестве поглощающих слоев CZTS.

Работа выполнена при финансовой поддержке Российского фонда фундаментальных исследоваиий (грант № 16-08-01234).

\section{Список литературы}

[1] Г.Ф. Новиков. Наука и технологии в промышленности, $\mathbf{1}$, 88 (2016).

[2] H. Katagiri, K. Jimbo, W.S. Maw, K. Oishi, M. Yamazaki, H. Araki, A. Takeuchi. Thin Sol. Film, 517, 2455 (2009).

[3] B. Shin, O. Gunawan, Y. Zhu, N.A. Bojarczuk, J. Chey, S. Guha. Progr. Photovolt: Res. Appl., 21, 72 (2012).

[4] Ingrid Repins, Carolyn Beall, Nirav Vora, Clay De Hart, Darius Kuciauskas, Pat Dippo, Bobby To, Jonathan Mann, Wan-Ching Hsu, Alan Goodrich, Rommel Noufi. Sol. Energy Mater. Sol. Cells, 101, 154 (2012).

[5] K. Wang, B. Shin, K.B. Reuter, T. Todorov, D.B. Mitzi, S. Guha. Appl. Phys. Lett., 98, 051912 (2011).

[6] T.K. Todorov, J. Tang, S. Bag, O. Gunawan, T. Gokmen, Y. Zhu, D.B. Mitzi. Adv. Energy Mater., 3, 34 (2013).

[7] D. Aaron, R. Barkhouse, O. Gunawan, T. Gokmen, T.K. Todorov, D.B. Mitzi. Progr. Photovolt.: Res. Appl., 20, 6 (2012).

[8] S. Ahmed, K.B. Reuter, O. Gunawan, L. Guo, L.T. Romankiw, H. Deligianni. Adv. Energy Mater., 2, 253 (2011).

[9] W. Shockley, H.Q. Queisser. J. Appl. Phys., 32, 510 (1961).

[10] T. Maeda, S. Nakamura, T. Wada. Jpn. J. Appl. Phys., 50, 04DP07 (2011).

[11] S. Chen, J. Yang, X.G. Gong, A. Walsh, S. Wei. Phys. Rev. B, 81, 245205 (2010).

[12] A. Nagaoka, K. Yoshino, H. Taniguchi, T. Taniyama, H. Miyake. J. Cryst. Growth, 341, 38 (2012).

[13] A. Nagaoka, K. Yoshino, H. Taniguchi, T. Taniyama, H. Miyake. J. Cryst. Growth, 354, 147 (2012).

[14] P. Bjirkman, J. Scragg, H. Flammersberger, T. Kubart, M. Edoff. Sol. Energy Mater. Sol. Cells, 98, 110 (2012).

[15] O. Vigil-Galán, M. Espíndola-Rodríguez, M. Courel, X. Fontané, D. Sylla, V. Izquierdo-Roca, A. Fairbrother, E. Saucedo, A. Pérez-Rodríguez. Sol. Energy Mater. Sol. Cells, 117, 246 (2013).

[16] M. Dimitrievska, A. Fairbrother, V. Izquierdo-Roca, A. PérezRodríguez, E. Saucedo. Photovoltaic Specialist Conf. IEEE 40th (2014).

[17] H. Katagiri, K. Jimbo, M. Tahara, H. Araki, K. Oishi. Mater. Res. Soc. Symp. Proc., 1165, 1165-M04-01 (2009).

[18] S. Delbos. Kesterite thin films for photovoltaics: a review, EPJ Photovoltaics, 3, 35004 (2012).

[19] K. Yamaguchi, T. Washio, K. Jimbo, H. Katagiri. The 21st International Photovoltaic Science and Engineering Conf., 2011, Fukuoka, Japan, 5B-3O-06.
[20] S. Chen, A. Walsh, X. Gong, S. Wei. Adv. Mater., 25, 1522 (2013).

[21] G.F. Novikov, K.V. Bocharov, Sci. Lett. J. (the former title is Phys. Express), 4, 21 (2014).

[22] A. Redinger, S. Siebentritt. Appl. Phys. Lett. 97, 092111 (2010).

[23] R.A. Wibowo, W.H. Jung, K.H. Kim. J. Phys. \& Chem. Solids, 71, 1702 (2010).

[24] I. Repins, C. Beall, N. Vora, C. DeHart, D. Kuciauskas, P. Dippo, B. To, J. Mann, Wan-Ching Hsu, A. Goodrich, R. Noufi. Sol. Energy Mater. Sol. Cells, 101, 154 (2012).

[25] M. Gapanovich, G. Novikov, K. Bocharov, Wei-Tao Tsai, Ming-Jer Jeng, Liann-Be Chang. 23rd Photovoltaic Science and Engineering Conf. (PVSEC-23). (Taiwan, China, 2013). Режим доступа: CD:/3-P-61.pdf. http://www.pvsec23.com/conf_news.html

[26] O. Gunawan, T.K. Todorov, D.B. Mitzi. Appl. Phys. Lett., 97, 233506 (2010).

[27] K.V. Bocharov, G.F. Novikov, T.Y. Hsieh, M.V. Gapanovich, M.J. Jeng. Semiconductors, 47, (3), 335 (2013). [К.В. Бочаров, Г.Ф. Новиков, Т.Y. Hsieh, М.В. Гапанович, М.J. Jeng. ФТП, 47, (3), 3105 (2013)].

[28] G. Novikov, K. Bocharov, T.Y. Hsieh, M.J. Jeng. Proc. 27th Eur. Photovoltaic Sol. Energy Conf. \& Exh. (27th EU PVSEC) (Frankfurt, Germany, 2012) p. 2851.

Редактор А.Н. Смирнов

\section{The lifetime of excess electron in $\mathrm{Cu}-\mathrm{Zn}-\mathrm{Sn}-\mathrm{Se}$ powder}

\author{
G.F. Novikov' ${ }^{1}$, M.V. Gapanovich ${ }^{1}$, V.F. Gremenok ${ }^{2}$, \\ K.V. Bocharov ${ }^{1}$, W.-T. Tsai ${ }^{3}$, Ming-Jer Jeng ${ }^{3}$, \\ Liann-Be Chang ${ }^{3}$ \\ ${ }^{1}$ Institute of Problems of Chemical Physics, \\ Russian Academy of Sciences, \\ 142432 Chernogolovka, Russia \\ ${ }^{2}$ Nauchno-Practical Center of National Academy \\ of Sciences of Belarus for Materials Science, \\ 220072 Minsk, Republic of Belarus \\ ${ }^{3}$ Department of Electronic Engineering, \\ Chang Gung University, \\ Taoyuan, Taiwan
}

Abstract The loss kinetics of current carriers in the powders $\mathrm{Cu}-\mathrm{Zn}-\mathrm{Sn}-\mathrm{Se}$ prepared by an ampoule solid-phase method of synthesis was studied by the method of time - resolved microwave photoconductivity (TRMC) in the band of $36 \mathrm{GHz}$ in the range of temperatures $200-300 \mathrm{~K}$. The lifetime of excess electrons at room temperature was appreciated as less than $5 \mathrm{~ns}$. The activation energy of recombination process was determined as $E_{a} \sim 0.054 \mathrm{eV}$. 